\section{A rare and potentially fatal complication of endoscopic submucosal dissection: iatrogenic type $B$ aortic dissection}
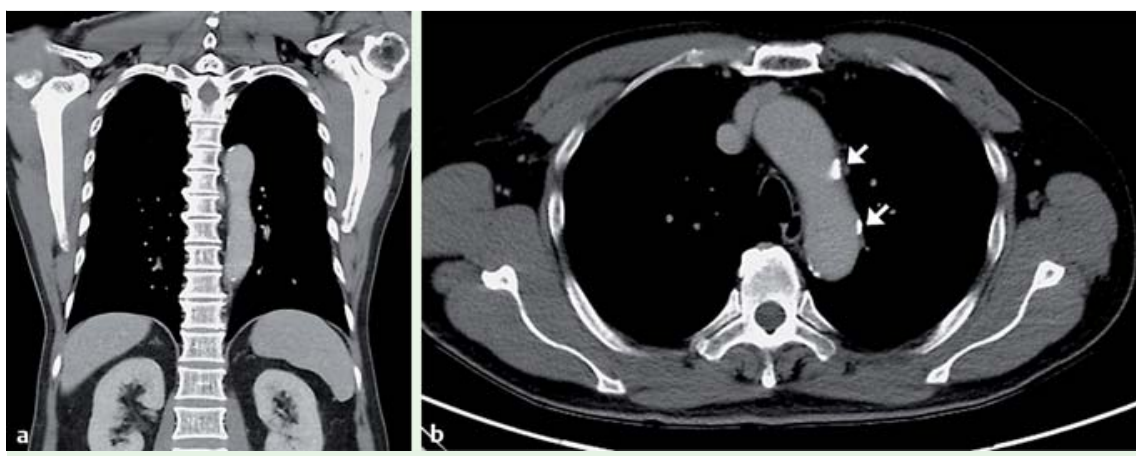

Fig. 1 A 59-year-old man with isolated lower esophageal squamous cell carcinoma received preprocedural computed tomography (CT) scans before endoscopy. a Coronal view; b axial view showing several calcified atheroma plaques at the aortic arch (arrows). There were no findings of aortic dissection.

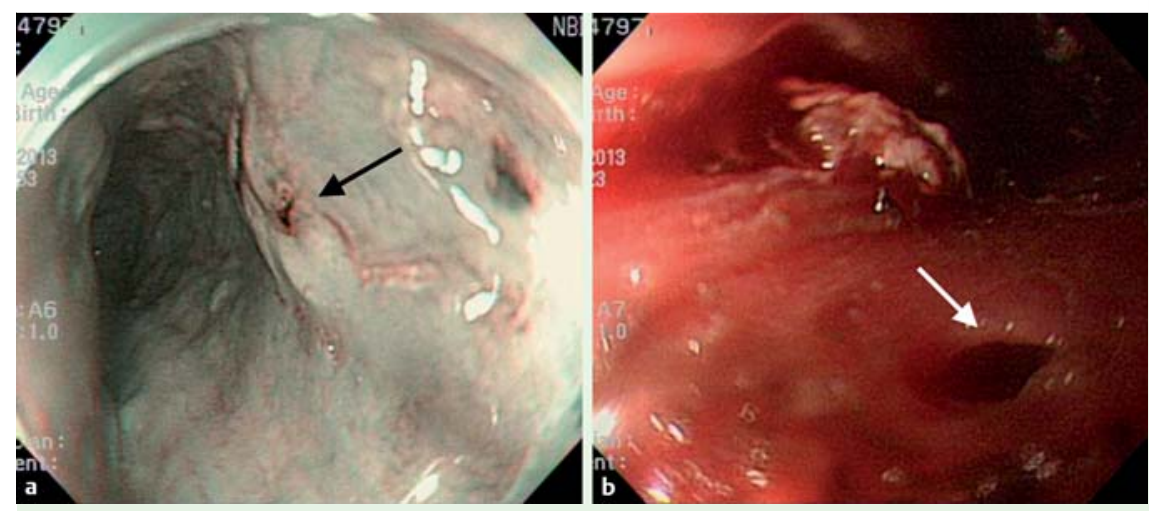

Fig. 2 a Irregular mucosal lesion (arrow) $1.5 \times 1.5 \mathrm{~cm}$ in size, $30 \mathrm{~cm}$ from the incisors over the right lower posterior aspect of the esophagus. $\mathbf{b}$ Esophagus perforation was suspected (arrow) when the patient developed hypertension, tachycardia, and subcutaneous emphysema.
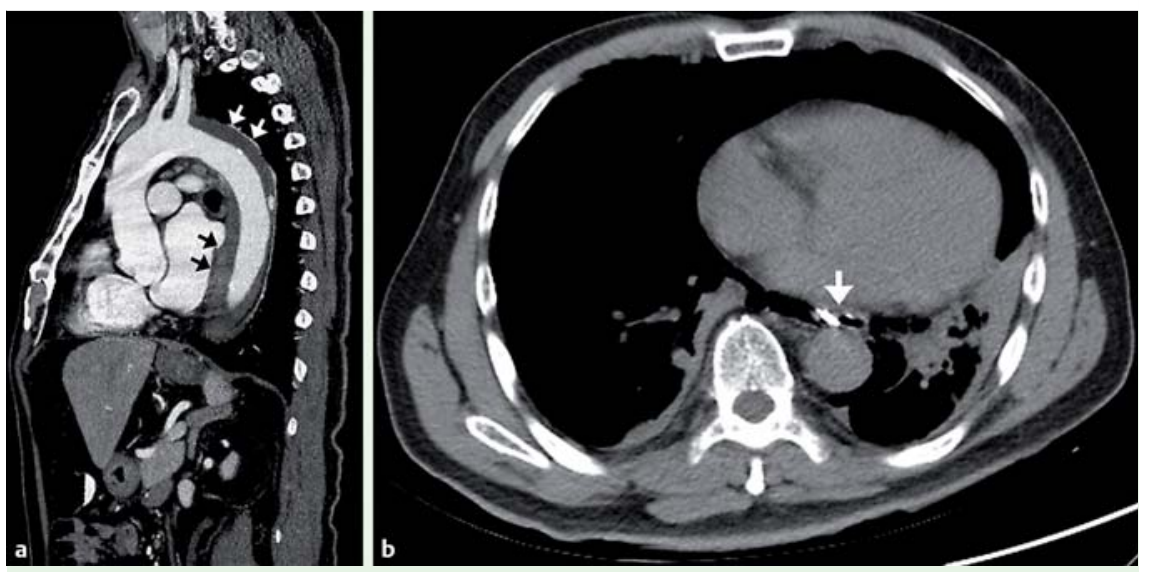

Fig.3 Postprocedural chest computed tomography (CT). a Contrast-enhanced sagittal view showed a 3.0-cm aneurysmal dilation between the aortic arch and celiac trunk compatible with acute type B aortic dissection (arrows). There was a hematoma and the dissection extended into the left subclavian artery. b The axial view showed the esophagus with endoclips (HX-610, Olympus Inc., Japan) ventrally adjacent to the descending aorta (arrow).
Esophagus perforation occurs in 3\%-4\% of endoscopic resections [1,2], however, the complication of aortic dissection has not been previously reported. We present the first case in this brief report.

A 59-year-old man with isolated lower esophageal squamous cell carcinoma, stage T1aN0M0 was scheduled for endoscopic submucosal dissection (ESD). The preprocedural chest computed tomography (CT) showed aortic plaques but was otherwise normal ( $\bullet$ Fig. 1 ). Total intravenous anesthesia with alfentanil and propofol was used for patient sedation during the endoscopy. An irregular mucosal lesion was found in the right dorsal lower third of the esophagus ( $\bullet$ Fig. 2 a). An ESD was performed using an IT Knife 2 (KD-611 L, Olympus Inc., Japan) and Hook Knife (KD-620LR, Olympus Inc., Japan) following injection of hyaluronic acid and indigo carmine.

The lesion could not be removed en bloc, therefore, it was removed in three pieces using a cap-fitted endoscope. After 45 minutes of procedure time, the patient became hypertensive and tachycardic. Subcutaneous emphysema was found over the lower neck and anterior chest wall. Because perforation was suspected ( $\mathbf{F i g . 2 b}$ ), the endoscopist closed the wound and suspended the procedure. Emergency chest $\mathrm{CT}$ revealed a new $3.0-\mathrm{cm}$ aneurysm dilation between the aortic arch and celiac trunk diagnostic of acute type B aortic dissection ( Fig.3). After conservative management of blood pressure and pain, the patient was discharged on post-procedural day 14 .

To prevent aortic intimal injuries, we note the following potential risk factors: (i) resection of lesions located in the dorsal region of the thoracic part of the esophagus; (ii) gastrointestinal lesions adjacent to pre-existing aortic disease, including atherosclerosis and cystic medial necrosis [3]; (iii) patients with poorly controlled hypertension. Aortic dissection as a result of perforation may be life-threatening if not identified and managed promptly. The endoscopist and anesthesia team need to be aware of this rare complication. Unexpected hypertension or tachycardia with subcutaneous emphysema during endoscopy warrants imaging of the thoracic structures following the procedure.

Endoscopy_UCTN_Code_CPL_1AH_2AZ

Competing interests: None 
Hsiang-Ling $\mathbf{W u}^{1,2, *}$, Ying-Hsuan $\mathrm{Tai}^{1,3, *}$, Ming-Chih Hou ${ }^{3,4}$,

M. Susan Mandell ${ }^{5}$, Mei-Yung Tsou ${ }^{1,3}$

${ }^{1}$ Department of Anesthesiology, Taipei Veterans General Hospital, Taipei, Taiwan

2 School of Medicine, National Defense University, Taipei, Taiwan

${ }^{3}$ School of Medicine, National Yang-Ming University, Taipei, Taiwan

${ }^{4}$ Endoscopy Center, Taipei Veterans General Hospital, Taipei, Taiwan

${ }^{5}$ Department of Anesthesiology, University of Colorado Health Sciences Center, Aurora, Colorado, United States

* Dr. Hsiang-Ling Wu and Dr. Ying-Hsuan Tai have made equal contributions to this paper.

\section{References}

1 Pech O, Gossner L, May A et al. Endoscopic resection of superficial esophageal squamouscell carcinomas: Western experience. Am J Gastroenterol 2004; 99: 1226

2 Yoshida M, Hanashi T, Momma K et al. Endoscopic mucosal resection for radical treatment of esophageal cancer. Gan To Kagaku Ryoho 1995; 22: 847

3 Leontyev S, Borger MA, Legare JF et al. Iatrogenic type A aortic dissection during cardiac procedures: early and late outcome in 48 patients. Eur J Cardiothorac Surg 2012; 41: 641-646

\section{Bibliography}

Dol http://dx.doi.org/

10.1055/s-0034-1390726

Endoscopy 2014; 46: E596-E597

(c) Georg Thieme Verlag KG

Stuttgart · New York

ISSN 0013-726X

\section{Corresponding author}

\section{Mei-Yung Tsou, MD, PhD}

Department of Anesthesiology

Taipei Veterans General Hospital No. 201 Sec. 2

Shipai Rd.

Beitou Dist.

Taipei 11217

Taiwan

Fax: +886-2-28751597

mytsou@vghtpe.gov.tw 